\title{
Eagle Syndrome and cervical disc herniation - combined symptomatology and treatment. Case report
}

\author{
Bartłomiej Kulesza', Paweł Szmygin', Witold Janusz' \\ ${ }^{1}$ Department of Neurosurgery and Paediatric Neurosurgery, Medical University, Lublin, Poland \\ Kulesza B, Szmygin P, Janusz W. Eagle Syndrome and cervical disc herniation - combined symptomatology and treatment. A case report. \\ J Pre-Clin Clin Res. 2018; 12(3): 89-91. doi: 10.26444/jpccr/95166
}

\begin{abstract}
Eagle syndrome is a rare condition where an abnormally elongated (over $3 \mathrm{~cm}$ ) calcified stylohyoid ligament irritates the adjacent soft tissues, causing a number of symptoms related to neck movements, such as local pain, odynophagia, dyphagia, otalgia and limited neck mobility. The symptoms depend from the structures involved: cranial nerves VII, IX, X and XII, as well as internal jugular vein and carotid artery. The conservative treatment of the condition includes: non-steroidal antiinflammatory, antyepileptic drugs, physiotherapy and neck exercises, steroids, and local anesthetic injections. The possible surgical approaches are internal (transoral) or external - transcervical and parapharyngeal. The case is presented of a female patient who suffered neck and shoulder pain from the combined occurrence of left-sided elongated styloid and cervical disc herniation. She was successfully treated with resection of the styloid via parapharyngeal approach.
\end{abstract}

\section{Key words}

Eagle syndrome, cervical disc herniation, parapharyngeral surgical approach, neck pain

\section{INTRODUCTION}

Eagle syndrome is a rare congenital condition in which an abnormally elongated styloid process or calcified stylohyoid ligament irritate the adjacent soft tissues, causing a number of symptoms: local pain, odynophagia, dyphagia, hypersalivation, otalgia, limited neck mobility and transient visual loss (amaurosis fugax). Characteristically, the symptoms aggravate with changes in head position. The surrounding structures that can be involved are: cranial nerves VII, IX, X and XII, as well as internal jugular vein and carotid artery [1]. Cases of carotid artery dissection or compression, causing recurrent TIA or ischemic stroke, have been reported [2]. Unless treated surgically with styloid process resection, the occlusion and damage to the crotid artery can be refractive to stenting [3]. In the case of conflict with the hypoglossal nerve, ipsilateral loss of tongue muscles and contralateral tongue deviation can be observed. The syndrome can be unilateral or, less frequently, bilateral. The imaging methods applied to diagnose the condition are: radiograph, orthopantogram and multi-slice 3D CT. The normal length of the process in adults is approximately $2.5 \mathrm{~cm}$ (ranging from $1.5-5 \mathrm{~cm}$ ), a styloid over $3 \mathrm{~cm}$ is considered elongated $[4,5]$. Some authors believe that the styloid is abnormal when its length exceeds one-third of the mandibular ramus in a panoramic view [6].

The syndrome was first described in 1937 by the American otolaryngologist Watt Weems Eagle, who estimated the incidence of the elongated styloid in the general population to be $4 \%$ [7]. Eagle believed that the ossification of the styloid complex occurs after surgical trauma (tonsillectomy) or local chronic irritation [8]. The condition most frequently affects female patients in the $3^{\text {rd }}-5^{\text {th }}$ decade of life [9]. In

Address for correspondence: Bartłomiej Kulesza, Department of Neurosurgery and Paediatric Neurosurgery, Medical University, Lublin, Poland

E-mail: kuleszabartek88@gmail.com

Received: 2 September 2018; Accepted: 15 September 2018 patients with temporomandibular disorder, the prevalence is reported to be as high as $76 \%$, which seems to confirm the secondary to irritation character of the ossification[10]. A familial occurrence of Eagle's syndrome was found and investigated by Morrison et al., who formulated the suggestion of an autosomal dominant heredity [11]. The authors point out that a similar condition - ossification of the posterior longitudinal ligament of spine (OPLLS) - prevalent in the Japanese population and causing cervical spine stenosis, has a traceable genetic etiology [12].

Palpation of the anterio-lateral submandibular region can reveal the presence of an elongated styloid process which can be a trigger for the typical neuralgia [13]. Sometimes, the pathological mass can be palpated in the tonsillar fossa [14]. The differential diagnosis must consider: temporomandibular joint disease, migraine headache, trigeminal, glossopharyngeal and sphenopalatine neuralgias [15].

The conservative treatment of the condition includes: nonsteroidal anti-inflammatory drugs, physiotherapy and neck exercises, steroids, local anaesthetic injections. According to the authors, satisfactory pain control can be attained with pregabalin and amitryptiline [16]. Transpharyngeal, imageguided steroid and lignocaine injections do not provide sustainable pain-relief, the symptoms recurring after 6-12 months [17]. In most cases, lack of significant improvement leads to surgical treatment. The possible surgical approaches are internal (transoral) or external - transcervical and parapharyngeal. The first is retromolar and paratonsillar and requires less surgical and recovery time and leaves no visible scar. The latter allows wider visualization of the operative field and involves less risk of infection $[18,19]$. A case series of 61 patients operated via submandibular external approach did not report any serious complications [20]. 


\section{CASE REPORT}

The patient, 54 year-old woman, a nurse, for five years had been having neck pain radiating to the left shoulder, and tingling and numbness of the left forearm and IV and V digits. In October 2014, the pain exacerbated, hand grip weakened and she began dropping objects from her left hand. She also noticed increasing stiffness of the neck and decreased mobility and pain as she tried to turn her head to the left. The pain spread to the left mandibular angle and left ear. The patient began suffering from odynophagia, vertigo and brief collapses. Additionally, she developed a hoarse voice.

The patient had been under close medical surveillance due to her previous neoplastic disease - in 2013 she had a hysterectomy because of menorrhagia, and histopathologic examination revealed a low grade endometrial cancer.

With the new symptoms she was referred to an otolaryngologist but neither the ear nor the parotid glands showed any abnormalities.

Cervical spine MRI and CT were performed and revealed cervical discs herniation - C5-C6 and C6-C7, as well as a calcified stylohyoid ligament. In the meantime, the patient consulted numerous specialists in different centers in Poland. A transoral approach to resect the enlarged styloid was proposed; however, the maxillofacial surgeon refused to perform the operation, anxious about the possible damage to the spinal cord caused by the positioning of the patient with concomitant cervical discopathy.

The patient was referred to a neurosurgeon for an elective surgical treatment. In February 2015, the patient underwent the surgery - open anterior C5-C6 and C6-C7 cervical discectomy with intervertebral cage stabilization. The skin incision was performed on the right half of the neck, according to the surgeon's preferences, enabling better exposure of the left nerve foramina. After completion of the discectomy, another incision - more cephalically and in the left submandibular area - was performed, the level confirmed by lateral x-ray with $\mathrm{C}$-arm. The structures encountered and retracted in the dissection were: platysma, submental vein, mylohyoid muscle, stylohyoid and geniohyoid muscle, submaxillary gland and thyreohyoid muscle. The bony structure of calcified ligament was palpated and identified, then resected with a bone rongeur. Care was taken not to leave any sharp edges. After haemostasis was obtained, the wound was closed in layers; resorbable intracutaneus suture was used for skin closure. Good healing of the wounds followed, leaving minimal scars and a very satisfying cosmetic effect.

The symptoms of the patient resolved completely with no neurological deficits observed. The patient was discharged on the $3^{\text {rd }}$ postoperative day and could restart her regular work after a month of rest.

\section{REFERENCES}

1. Baig S, Patil N, Considine N. An unusual cause of recurrent neck pain calcified stylohyoid ligament.J Coll Physicians Surg Pak 2012; 22: 258-60

2. Sveinsson O, Kostulas N, Herrman Lars: Internal carotid dissection caused by an elongated styloid process (Eagle syndrome). BMJ Case Rep. 2013 Jun 11;2013

3. Hooker JD, Joyner DA, Farley EP, Khan. Carotid stent fracture from Stylocarotid Syndrome. Radiology Case. 2016 Jun; 10(6):1-8

4.Han MK, Kim do W, Yang JY. Non surgical treatment of Eagle's syndrome: a case report. Korean J Pain. 2013; 26 (2): 169-72

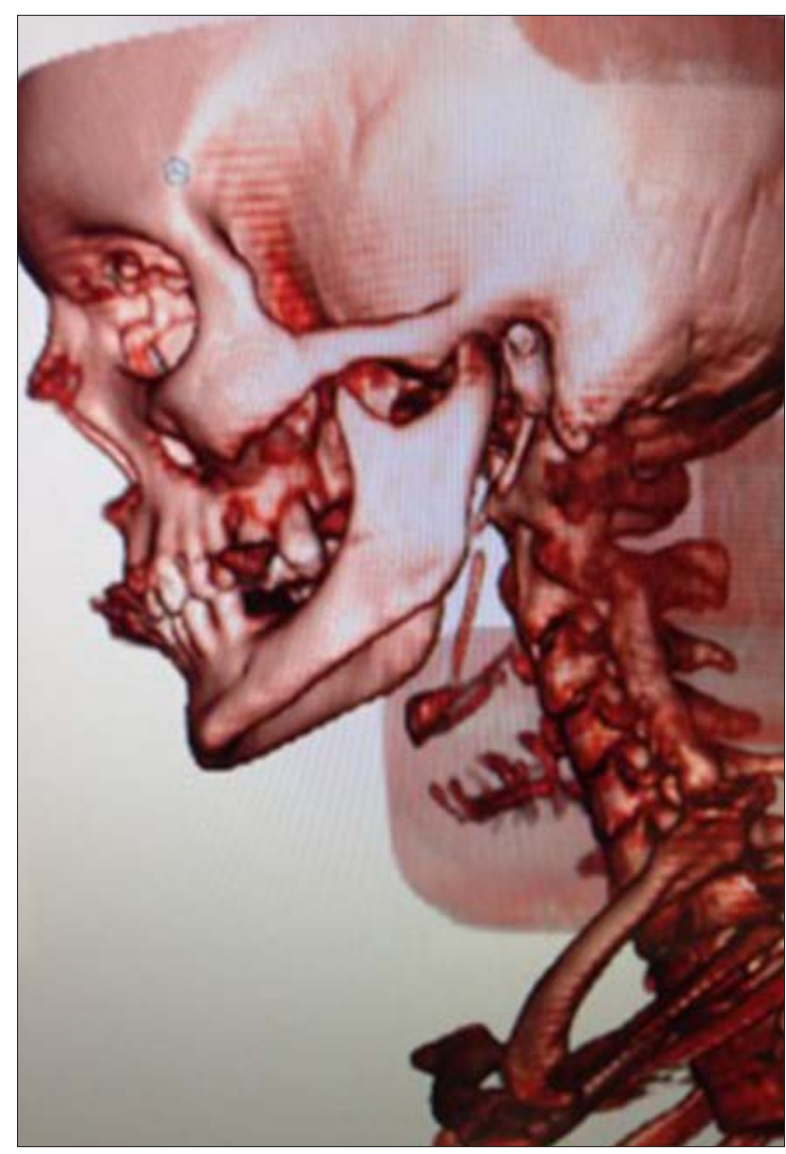

Figure 1. Calcified left stylohyoid ligament extending from mastoid process to the hyoid bone along the ramus of mandible - 3D reconstruction of preoperative CT scan

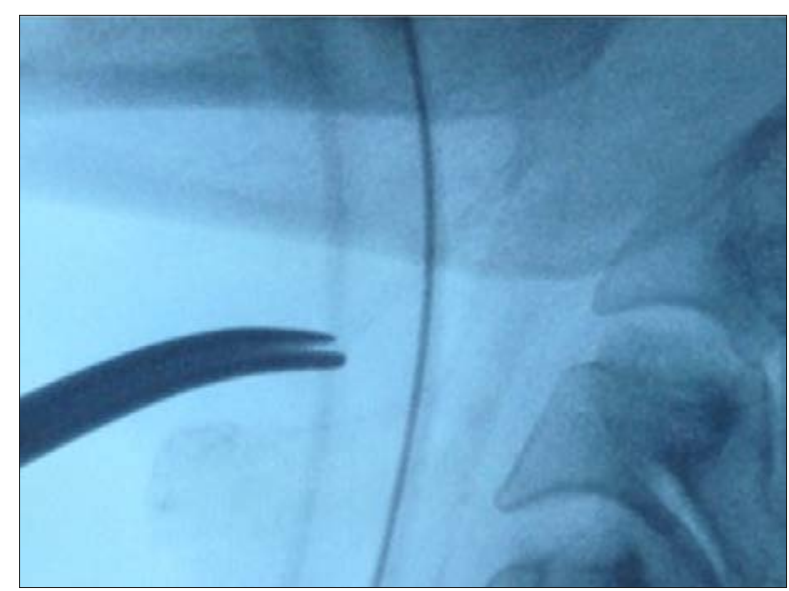

Figure 2. Intraoperative lateral radiograph. Pale shadow of calcified stylohyoid ligament with the clamp locked on it right below the body of the mandible

5. Keur JJ, Campbell JP, McCarthy JF, Ralph WJ. The clinical significance of the elongated styloid process. Oral Surg Oral Med Oral Pathol. 1986; 61(4): 399-404.

6. Moon CS, Lee BS, Kwon YD, Choi BJ, Lee JW, Lee HW, Yun SU, Ohe JY. Eagle's syndrome: a case report. J Korean Assoc Oral Maxillofac Surg. 2014;40(1): 43-7

7. Eagle WW. Elongated styloid process: Symptoms and treatment. Arch Otolaryngol 1958; 64: 172-6

8. Eagle WW: Elongated styloid process: further observation and a new syndrome. Arch Otolaryngol 1948;47:630-40

9. Murthy PS, Hazarika P, Mathai M, Kumar A, Kamath MP. Elongated styloid process: an over view. Int J Oral Maxillofac Surg. 1990; 19(4): $230-1$ 


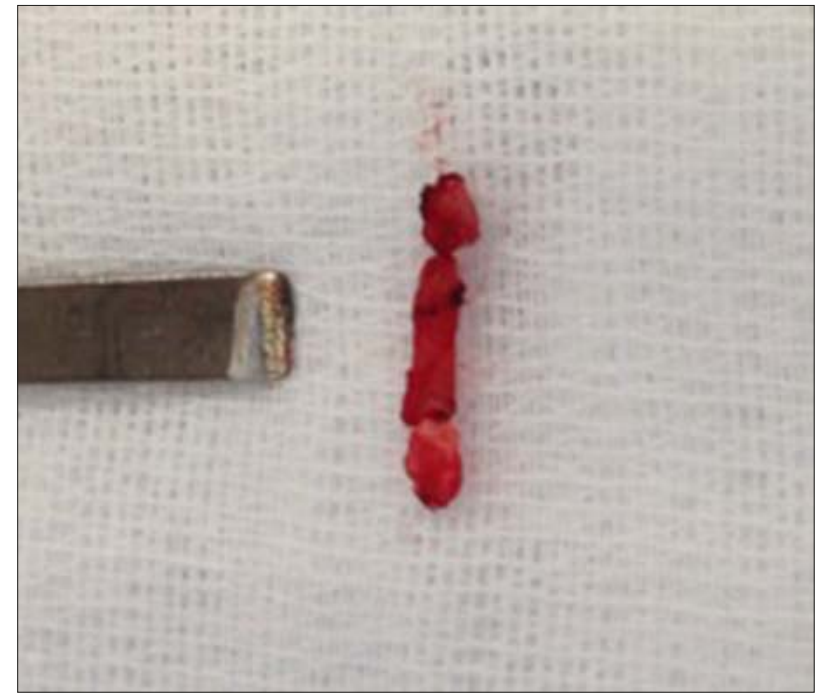

Figure 3. Resected specimen of the calcified stylohyoid ligament

10. De Andrade KM, Rodrigues CA, Watanabe PC, Mazzetto MO. Styloid process elongation and calcification in subjects with tmd: clinical and radiographic aspects. Braz Dent J 2012;23:443-50
11. Morrison PJ, Morrison RJ, McKinstry CS. Familial ossification of the stylohyoid ligament in a three generation family - a new clinical entity displaying autosomal dominant inheritance. Brit J Radiol, 85 (2012), 458-459

12. Kong Q, Ma X, Li F, Guo Z, Qi Q, Li W. COL6A1 polymorphisms associated with ossification of the ligament flaum and ossification of the posterior longitudinal ligament. Spine (Phila Pa 1976) 2007; 32:2834-8

13. Fusco DJ, Asteraki S, Spetzler RF. Eagle's syndrome: embryology, anatomy and clinical management. Acta Neurochir (Wien) 2012; 154(7): 1119-26

14. Elimairi I, Baur DA, Altay MA, Quereshy FA, Minisandram A: Eagle's Syndrome. Head and Neck Pathol (2015) 9: 492-495

15. Jaju PP, Suvarna V, Parikh NJ. Eagle's syndrome: an enigma to dentists. J Indian Acad Oral Med Radiol. 2007; 19(3):424-9

16. Taheri A, Firouzi-Marani S, Khoshbin M. Nonsurgical treatment of styloid (Eagle) syndrome: a case report. J Korean Assoc Oral Maxillofac Surg 2014; 40:246-49

17. Diamond LH, Cotrell DA, Hunter MJ, Papageorge M. Eagle's syndrome: a report of 4 patients treated using a modified extraoral approach. J Oral Maxillofac Surg. 2001; 59:1420-6

18. Mendelsohn AH, Berke GS, Chheteri DK. Heterogeneity in the presentation of Eagle's syndrome. Otolaryngol Head Neck Surg 2006; 134:389-93

19. Strauss M, Zohar Y, Laurian N. Elongated styloid process syndrome: intraoral versus external approach for styloid surgery. Laryngoscope $1985 ; 95: 976-9$

20. Ceylan A, Koybasioglu A, Celenk F.: Surgical treatment of elongated styloid process: experience of 61 cases. Skull Base 2008; 18:289-95. 